\title{
The Stanford Encyclopedia of Philosophy
}

\section{A university/library partnership in support of scholarly communication and open access}

$\mathbf{O}$ ne major and recurrent theme of the scholarly communication column is the question, What can librarians do to help bring about fundamental changes in the system of scholarly communication? This question is at the heart of both the ACRL Scholarly Communications Initiative ${ }^{1}$ and the Scholarly Communications Toolkit. ${ }^{2}$ To answer this question, several principles of reform have emerged: ${ }^{3}$

- the broadest possible access to published research;

- increased control by scholars and the academy over publishing;

- fair and reasonable prices for scholarly information;

- open access to scholarship;

- innovations in publishing that reduce distribution costs, speed delivery, and extend access to scholarly research;

- quality assurance in publishing through peer review;

- fair use of copyrighted information for education and research purposes; and

- preservation of scholarly information for long-term future use.

Though different strategies for achieving reform have been identified, one that appears most frequently is that of building partnerships to help bring about change. One central ACRL document indicates that "the purpose of the ACRL scholarly communications initiative is to work in partnership with other library and higher education organizations to encourage reform in the system of scholarly communications and to broaden the engagement of academic libraries in scholarly communications issues." ${ }^{\prime 4}$ The publishing and funding models of the Stanford Encyclopedia of Philosophy (SEP) do precisely that, both by a) promoting the goals, principles, and methods identified above, and b) presenting the kind of enterprise that warrants "engagement" and support from academic libraries.

\section{SEP's publishing model}

SEP organizes the profession of philosophy to collaboratively maintain a dynamic open access reference work. It was conceived, implemented, and is now administered by a group of academics, and, in particular, by philosophers with knowledge of Unix powercomputing, Perl-CGI programming, HTML, and the Web.

After developing a proof of concept from 1995-97, SEP staff won successive grants from NEH (1998-2000), NSF (2000-03), and NEH (2003-05) to build content and a "Web content management system" that could support the operational workflow needed in a dynamic reference work. Our system allows us to manage communications and production schedules among 1,004 volunteer authors and 100 volunteer subject editors, with a paid staff of 1.7 persons. Quality control starts with

Edward Zalta is senior research scholar at Stanford University's Center for the Study of Language and Information and the principal editor of the Stanford Encyclopedia of Philosophy, e-mail: zalta@stanford.edu (c) 2006 Edward Zalta 
the Stanford University Philosophy Department, which vets the appointments to the SEP Editorial Board. The members of the board, in turn, commission and referee the entries and updates to entries. Authors and editors can use password-protected Web interfaces to log onto secure SEP servers and conduct SEP business and thereby collaboratively produce the content; these interfaces can be used to issue invitations, accept invitations, post entries, referee entries, edit entries, compare original and revised versions of entries side-by-side with the differences highlighted, etc.

All entries, and updates to entries, are rigorously refereed prior to publication on the Web. Our backend Web content management system keeps track of the state of every entry on a daily basis. It not only identifies which entries require immediate attention from the central staff, but also sends out periodic reminders to authors and editors with approaching or past deadlines. Every entry is put onto a schedule on which it must be updated once every two to five years. Finally, we make a fixed copy of SEP every quarter, and these quarterly archives provide stable content for purposes of citation.

This is a publishing model that is rather different from a journal. Our production routines are asynchronous (each entry is produced on its own customized schedule), and thus our workflow control system is far more complex than that required by journals published on a regular schedule. We now publish an average of ten entries a month, and five updates a month, at a total project cost of $\$ 191,000$ a year for AY2005-06 (\$154,000 of this total is for salaries and benefits). SEP has mirror sites at three other universities, all of which are donating their resources. These sites synchronize to the Stanford server on a nightly basis and provide: a) faster access to other parts of the globe, b) continuous uptime should the Stanford server need to go offline for hardware/software upgrades, and c) extra layers of digital preservation. Finally, our copyright policy works for the author: authors retain copyright to reprint their articles in any fixed medium, but give SEP an exclusive license to publish the entry on the Web. ${ }^{5}$

\section{SEP's impact}

SEP provides the philosophical profession and the general public alike with highquality scholarship on a variety of topics relevant to the human condition. From its inception in 1995, SEP has been open access. The SEP has 766 entries now online, with an average length of more than 10,000 words per entry. During the 2005-06 academic year, our Stanford server has been accessed up to 750,000 times a week, and most of our entries figure prominently in the list of matches that Web-based searchengines return when the topic of the entry is part of the query-string. SEP has a wide readership ranging from high school students and undergraduates to academics in a variety of professions and general readers. Our readers span the globe from more than 170 countries around the world. This large readership highlights SEP's value for research, education, and public access to the humanities. To see how widely SEP is read across the academic spectrum at your institution, just type in your domain name at leibniz.stanford.edu/cgi-bin/library /usage.cgi.

\section{SEP's funding model}

After investigating various long-term funding models, a committee consisting of representatives of Stanford, International Coalition of Library Consortia, SPARC, and SOLINET came up with the idea of creating a partnership that builds a permanent operating fund for SEP, but which protects the money that libraries contribute to the fund. A 4.8 percent yearly payout on a $\$ 4.125$ million fund would secure SEP's operating budget for the long term. The partnership calls for 1) Stanford University to raise $\$ 1.125$ million towards this fund (primarily from private donors), and 2) the large umbrella library organizations to raise $\$ 3$ million (primarily from libraries worldwide at institutions offering degrees in philosophy). SOLINET will collect library contributions and turn them over to Stanford under a contract that protects library contributions in that: a) 
Stanford is allowed to use library money only for the support of SEP, and b) if the SEP project ever terminates, Stanford will return the money the libraries have contributed with any interest and appreciation (in excess of the payout) earned while Stanford was entrusted with the funds.

This arrangement (and the contract to support it) has been approved by the National Endowment for the Humanities (NEH). The NEH Office of Challenge Grants has endorsed the funding model by giving SOLINET a matching grant: for every 3 raised from the libraries, NEH will match with 1 , up to $\$ 500,000$ from NEH. ${ }^{6}$ To make these institutional arrangements even more attractive to libraries, we have set up a membership organization, the Stanford Encyclopedia of Philosophy International Association (SEPIA). SEPIA is sponsored by Indiana University Libraries and is a part of SOLINET. SOLINET collects library contributions in the form of membership dues to SEPIA, and there are certain benefits that come with membership:

- Library money will be protected in the manner described above.

- Library membership dues can be paid as a one-time payment or spread over three years (thereby avoiding an ongoing cost).

- Libraries get the right to download SEP's quarterly archives as a single compressed file (thereby building its collection).

- The large library organizations will get representation on a SEP governing board.

- Libraries will receive public credit, both locally and globally:

- SEP pages delivered to contributing institutions have branded acknowledgements (so that local readers will see that their libraries have contributed), and

- The name of the library will be added to SEP's public commitments page.

\section{Observations: What does it all mean?}

SEP is a true university-library partnership and presents a new model for open access that dovetails precisely with the goals and objectives of the scholarly communication community. In particular SEP provides:
- the broadest possible access to published research;

- control by scholars, the academy, and the library community over publishing;

- fair and reasonable prices for receiving the benefits of membership in SEPIA;

- completely open access to scholarship;

- innovations in publishing that reduce distribution costs, speed delivery, and extend access to scholarly research;

- quality assurance in publishing through peer review;

- fair use of copyrighted information for education and research purposes; and

- preservation of scholarly information for long-term future use.

SEP can survive and thrive only to the extent that every academic and research library serving those with an interest in philosophy_large and small, public and private - participates by shouldering a fraction of the burden. If a library joins SEPIA (www. libraries.iub.edu/index.php?pageId=3563) and contributes to the SEP Library Fund, Stanford will hold its money in trust in a growing endowment that can be used only for budgeted expenses of the encyclopedia. Moreover, library money does not disappear into a black hole, but is instead put to work (or returned, should the project ever terminate).

Once SEP is funded, there are no further fees, and open access is ensured in perpetuity. Membership in SEPIA additionally carries the perks described above.

Perhaps, most importantly, participation in this partnership enables libraries to make a difference; your library would do its part in making an investment that furthers both scholarly communication and open access.

\section{Notes}

1. Ray English, "The ACRL Scholarly Communications Initiative," CERL News 65, no. 8 (2004): "The purpose of the initiative is to enable ACRL to play a prominent role, in cooperation with other organizations, in working

(continued on page 507) 